\title{
Prescribing non-steroidal anti-inflammatory drugs: a prospective study of patients' preference
}

\author{
D. L. SCOTT $\dagger$ \\ M.R.C.P. \\ S. RoDEN* \\ M.Sc., M.P.S. \\ T. S. LOW-BEER* \\ F.R.C.P. \\ L. TAKAVARASHA* \\ M.Sc., M.P.S. \\ * Selly Oak Hospital, Birmingham, and + Rheumatism Research Wing, Queen Elizabeth \\ Hospital, Birmingham
}

\begin{abstract}
Summary
Thirty-six patients with rheumatoid arthritis were allocated at random to one of 3 groups prescribed 4 different non-steroidal anti-inflammatory drugs (NSAID). Each drug was given for one week over 4 consecutive weeks in a balanced order. The patients were then asked to select one NSAID for continuation therapy and were followed-up 6 months later. The success of the patient selection method was compared with that of physician selection by retrospectively surveying NSAID prescribing in 164 patients attending 2 other rheumatology units over a 5-year period.

Only $72 \%$ of patients in the prospective study felt able to choose one of the NSAIDs and $31 \%$ of these had discontinued the chosen drug within 6 months. In the retrospective study, $40 \%$ changed their NSAID within 6 months.
\end{abstract}

\section{Introduction}

Patients with rheumatoid arthritis often require long-term treatment with non-steroidal antiinflammatory drugs (NSAIDs). However, there are 39 such preparations listed in the current Monthly Index of Medical Specialities (MIMS) (August 1981) and selection of the one which will provide maximum efficacy and the minimum of side effects for an individual patient is often a long and tedious process. Gumpel (1978) suggested that this may be partially resolved by the 'mini-pack, multi-drug, patient-assessed clinical trial'. A similar scheme has been evaluated at Selly Oak Hospital. The satisfaction which patients obtained from selecting a NSAID in this way was assessed by whether they continued on that drug for at least six months. The same criterion was used to assess the value of NSAIDs chosen by a physician in two rheumatology centres in the West Midlands over a 5-year period.
Patients and methods

All patients with definite or classical rheumatoid arthritis who attended the rheumatology clinic at $ᄋ$ Selly Oak Hospital and required treatment with an effective NSAID were considered for entry to the study. Those who had recently started gold, penicillamine or steroid therapy or who had changed their dose of these drugs within the previous two month? were excluded. Patients with a history of pept ulceration were also excluded. Thirty-six patient 30 women and 6 men were selected. Their meat age was $59 \pm 8$ years, and the duration of their rheumatoid disease ranged from 6 months to 32 years (mean 5 years). Each patient was randomly allocated to one of the following treatment groups (all drugs, in quantities stated, given three times daily): (a) ibuprofen $400 \mathrm{mg}$, benorylate $1500 \mathrm{mg}$, indomethacin $50 \mathrm{mg}$, fenoprofen $600 \mathrm{mg}$; (b) ibuprofen $400 \mathrm{mg}$, sulindac $100 \mathrm{mg}$, naproxen $250 \mathrm{mg}$, ketoprofen $50 \mathrm{mg}$; (c) ibuprofen $400 \mathrm{mg}$, enteric coated aspirin $1200 \mathrm{mg}$, diclofenac $50 \mathrm{mg}$, flurbiprofen $100 \mathrm{mg}$.

All drugs were taken with or after meals, three times daily for 7 days over a consecutive 4-week period. To avoid a possible order effect and to reduce any 'carry over' of effect, the drugs in each group were given in a balanced order. Although the patients were encouraged to complete each 7-day course, they were given the option of starting the next treatment if they were unable to tolerate a particular drug. A supply of paracetamol was also issued in case additional analgesia was required; the number of tablets consumed was recorded.

Each patient was asked to keep a daily record of their duration of morning stiffness, joint pain, adverse reactions and the number of paracetamol tablets required using a form similar to that described by Gumpel. At the end of each treatment, 
TABLE 1. Patients' assessments of method with reference to the number of selections made and adverse reactions

\begin{tabular}{lccc}
\hline $\begin{array}{l}\text { Patients' } \\
\text { assessments }\end{array}$ & $\begin{array}{c}\text { Total number } \\
\text { in each } \\
\text { assessment } \\
\text { group }\end{array}$ & $\begin{array}{c}\text { Number in each } \\
\text { assessment } \\
\text { group choosing } \\
\text { a new NSAID }\end{array}$ & $\begin{array}{c}\text { Number in each } \\
\text { assessment group } \\
\text { reporting one or } \\
\text { more adverse } \\
\text { reactions }\end{array}$ \\
\hline Very good & 6 & 6 & 5 \\
Good & 16 & 14 & 9 \\
Satisfactory & 5 & 4 & 3 \\
Poor & 5 & 2 & 5 \\
Very Poor & 4 & 0 & 4 \\
\hline
\end{tabular}

they commented on the suitability of the drug. Instructions on completion of the forms and the aims of the study were given both verbally and in writing. At the end of the 4-week period, the patients returned to the clinic and were asked which NSAID they wished to continue. They also assessed the method used for selection in terms of the categories listed in Table 1.

Six months later, each patient's clinic notes were reviewed with reference to their current NSAID therapy, and any change from the drug selected in the study was noted, together with the reasons for discontinuation.

Three patients withdrew before completing the scheme; 2 decided not to participate after leaving the clinic, and one was admitted to hospital with an unrelated problem. They were replaced with another 3 patients who all completed the study.

\section{Retrospective study}

The records of 182 randomly selected patients, 123 women and 59 men, attending 2 rheumatology units in the West Midlands over a 5-year period were reviewed retrospectively; 127 had rheumatoid arthritis, 20 osteoarthritis and the remainder other rheumatic diseases. Their mean age was $55 \pm 15$ years and the duration of their disease ranged from 6 weeks to 43 years (mean 9 years); 164 were taking NSAIDs and the number of patients who changed their NSAID within 6 months of starting was recorded.

\section{Results \\ Prospective study}

Twenty-six patients $(72 \%)$ chose to continue with one of the NSAIDs taken during the study. Eight of the 10 patients making no choice elected to return to one of the NSAIDs which they had taken before entry, indomethacin suppositories in four instances. All 10 patients had experienced at least one adverse reaction during the scheme. Overall, 26 patients had one or more adverse reactions, and these occurred in $31 \%$ of NSAID exposures. The majority of reactions affected either the nervous system (for instance dizziness and headache) or the upper gastrointestinal tract. The other reactions included skin rashes and non-specific feelings of being generally unwell. Of the NSAID exposures $17 \%$ were spontaneously reported as being ineffective.

The patients' assessments of the method of NSAID selection are summarized in Table 1. Nine patients commented that one week was insufficient for them adequately to assess each drug.

After 6 months, only 18 of the 26 patients who had selected a NSAID in the study were still taking it. Eight patients $(31 \%)$ had discontinued their chosen drug, four owing to severe gastrointestinal side effects, and the other four had subsequently found it ineffective.

\section{Retrospective study}

Of the 164 patients prescribed NSAIDs in the 2 West Midlands Centres, $66(40 \%)$ changed their NSAID within 6 months of starting the drug and $71(43 \%)$ continued for longer than 6 months. Adverse reactions were recorded in $16 \%$ of NSAID exposures.

In 27 cases, there were either insufficient data to assess the duration of therapy, or patients had not yet been followed-up for months after the NSAID had been prescibed.

\section{Discussion}

The multiplicity of NSAIDs makes it difficult to select the most suitable drug for an individual patient. Most clinical trials of NSAIDs are shortterm and only compare a limited number of compounds in carefully selected patients, although a few studies have compared multiple NSAID administration or their use over prolonged periods (Huskisson et al., 1976; Aylward et al., 1975; Pinals et al., 1977).

Patient preference is an attractive basis for the selection of a NSAID but the results of this prospective study do not support those obtained by Gumpel (1978) who recorded a $100 \%$ success rate in 50 patients. In the present study, $25 \%$ of the patients considered that one week was too short a period to assess each drug and there may also have been some 
carry-over of effect from one treatment to the next. In Gumpel's study, each drug was given for 5 days only, always, apparently in the same order. Also in contrast to his results, $25 \%$ of patients in the present study considered the selection method to be poor or very poor and only $72 \%$ selected a NSAID from their regime. Furthermore, successful selection did not necessarily result in a NSAID of long-term value since, by six months, $31 \%$ of the patients had discontinued the chosen drug.

The retrospective review of conventional NSAID prescribing showed that $40 \%$ of patients changed their therapy within 6 months of commencement, usually owing to adverse reaction or loss of effect. Although the choice of six months is arbitrary and therefore open to criticism, it was considered to be a reasonable distinction between short- and long- term therapy. Since both studies revealed a similar frequency of NSAID changes, it was concluded that $\stackrel{\AA}{\complement}$ in the long term, the selection of these drugs by a $ᄃ$ physician is as successful and both simpler and $\overrightarrow{\vec{F}}$ cheaper than selection by the patient.

\section{References}

Aylward, M., Parker, R.J., Holly, F., Maddock, J. \& $\overline{\bar{\omega}}$ DAVIES, D.B.S. (1975) Long term study of indomethacin $\Phi$ and alclofenac in treatment of rheumatoid arthritis. British Medical Journal, 2, 7.

GUMPEL, J.M. (1978) Which anti-inflammatory drug in rheumatoid arthritis? British Medical Journal, 2, 256.

Huskisson, E.C., Woolf, D.L., Balme, H.W., ScotT, J. \& FraNKLYN, S. (1976) Four new anti-inflammatory drugs: $\vec{\omega}$ responses and variations. British Medical Journal, 1, 1048.

Pinals, R.S., Runge, L.A., JABbS, J.M. \& MAdDi, V.I. (1977)至 New non-steroidal anti-inflammatory agents. Prospective 3 survey of relative merits. New York State Journal of is Medicine, 77, 1268. 